\title{
Assessing dietary intake and its relation to growth in British children
}

\section{By M. Nelson, Dunn Nutrition Laboratory, Cambridge}

Attempts to relate the quality of diet to growth in British children are plagued by two persistent anomalies. In the first, workers have found no consistent relationship between individual intake and growth. The biggest eaters are not necessarily the biggest individuals. As Widdowson said in 1947 , 'the present study has been unable to bring to light the laws which relate the height, weight, size and surface area of any one person to his calorie intake or calorie requirement'. We are still very much in the dark.

The second anomaly relates to groups of individuals from different social classes. The average energy and nutrient intakes amongst children from the manual social classes (III manual, IV and V) tends to be higher than that of children from non-manual classes (I, II and III non-manual) (Widdowson, 1947; Bransby \& Fothergill, 1954; Department of Health and Social Security, 1975; A. E. Black, unpublished results), while at the same time manual workers' children are on average shorter than non-manual workers' children (Durnin et al. 1974; Department of Health and Social Security, 1975; A. M. Thomson, unpublished results). It is this second anomaly that $I$ wish to try and resolve.

Briefly, the limited information available in Britain suggests that the quality of the social and physical environment mediates the effectiveness of diet in promoting growth and health. The use of a common standard (e.g. the recommended dietary intake; RDI) to assess dietary adequacy in different environments does not take into account these differences in dietary effectiveness. By dividing the population into two subgroups using a suitable parameter of environmental quality (e.g. social class), and by assessing diet and growth in these two groups independently, the second anomaly can be resolved, as we shall see. First we must consider how diet and growth are best assessed.

\section{Dietary surveys}

Any attempt to relate diet and growth must be based on reliable and representative measurements of individual intakes. For this, we require either a $7 \mathrm{~d}$ weighed intake (Marr, 1965) or an equivalent accurate method (Nettleton and Nelson, unpublished results). As we shall see, it is necessary to be able to establish not simply the mean group intake but also the degree of individual variation around the mean. Therefore surveys of shorter duration (except in circumstances where the day-to-day variations in diet are known to be small) or of lesser accuracy will not be adequate for elucidating relationships between diet and growth.

\section{Standards of assessment}

Conventionally, measurements of nutritional status are compared with predetermined standards of adequacy. In the case of diet, this is usually the 
Recommended Intakes of Nutrients for the United Kingdom (Department of Health and Social Security, 1969). These recommendations for nutrient intake are intended to be 'sufficient or more than sufficient for the nutritional needs of practically all healthy persons in a population', with the exception of energy which is intended to reflect average requirements. It follows that failure on the part of an individual to reach the RDI for a given nutrient does not constitute undernutrition, as the RDI are designed to reflect the needs of groups rather than individuals. However, as a group mean falls further and further below the RDI, the likelihood increases that the intakes of some of the individuals within the group will fall below their own personal requirement. Which individuals will be affected cannot be determined, nor is the degree of risk associated with a given level of intake consistent from one group to another.

Standards also exist for the clinical, biochemical and anthropometric measurements which may be part of a nutritional status survey, and these can be used to help assess whether or not the diet is adequate to maintain health and growth. For simplicity of argument, I shall assume that height is the best indicator of long-term nutritional status in Britain, and that Tanner \& Whitehouse growth standards (Tanner et al. 1966) adequately describe the normal distribution of height within the population.

\section{Diet and growth}

Let us look at the two diets (a) and (b) in Table 1 . They represent the mean intakes of two groups of children in two different dietary surveys carried out in Britain in the last ro years, (Black et al. 1976; Nelson \& Naismith, 1979). The methods of determination of diet are comparable.

Superficially, the adequacy of the two diets is similar, not only for the four nutrients presented here but for the remainder of the diet as well. Yet if we compare the patterns of growth of these two groups of children, we see in Fig. I that the distributions of height are almost mirror images, one group being significantly taller than the other. We must answer two questions: how can two such apparently similar diets be associated with two such different patterns of growth? What standard(s) of dietary adequacy can be used which will reflect the observed differences in growth?

Table 1. Mean nutrient intakes of two groups of children, expressed as a percentage of the Recommended Intake

(Values in parentheses are coefficients of variation (standard deviation $\div$ mean))

$\begin{array}{lrr}\text { Nutrient } & \text { Group (a) } & \text { Group (b) } \\ \text { Energy } & 89(0.21) & 86(0.34) \\ \text { Protein } & 11 \text { I (0.23) } & 116(0.39) \\ \text { Iron } & 82(0.31) & 98(0.40) \\ \text { Thiamin } & 113(0.28) & 114(0.33)\end{array}$




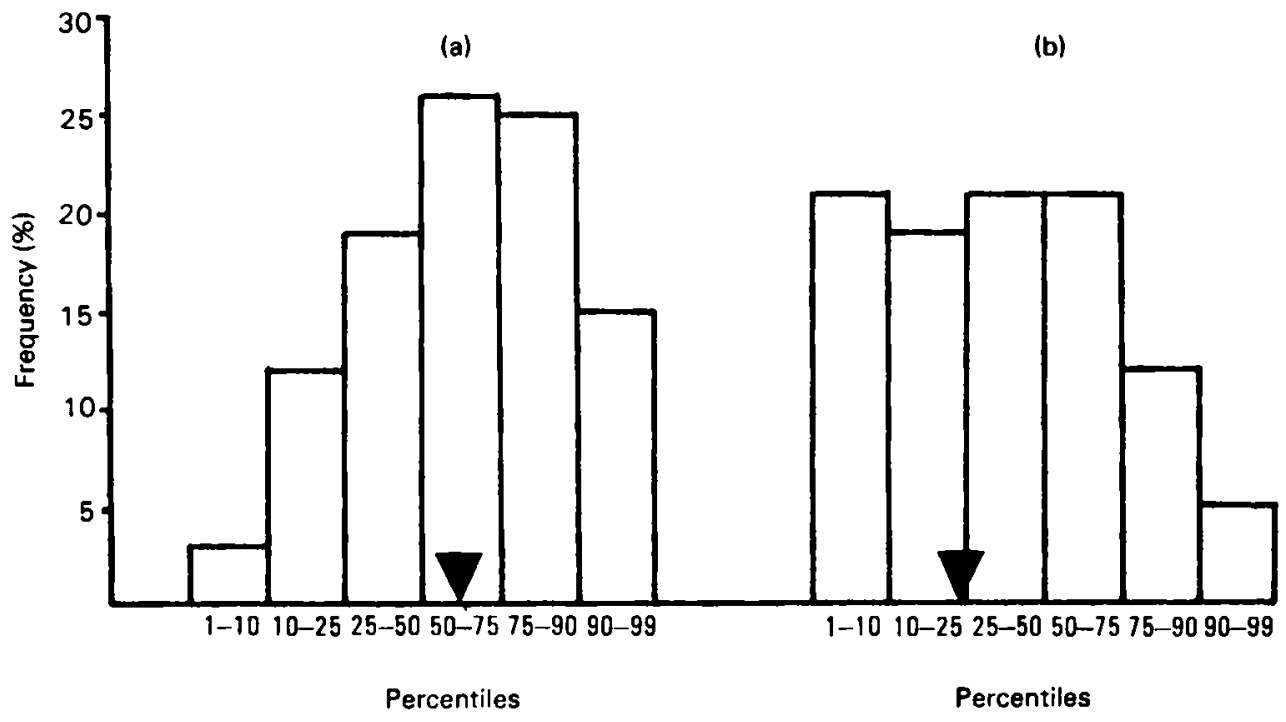

Fig. I. Height distribution of two groups of white, British children, by percentile groups (based on Tanner et al. 1966).

(a) Newcastle preschool children; non-manual.

(b) London children ( $\mathrm{I}-\mathrm{I} 2$ years); manual.

$\nabla$ indicates mean.

In order to answer the first question, it is necessary to consider the composition of the two groups of children. Group (a) was made up of preschool children aged 1.5 to 3.5 ycars from non-manual social class families in Newcastle. Group (b) was comprised of children between the ages of $I$ and 12 years from very poor families in London.

The first possible explanation for the differences in growth is that the relationship of RDI to true requirement changes with age, and that older children have a much greater requirement than the RDI would indicate. Unfortunately, the reverse appears to be the case. In a recent survey of Cambridge children of apparently normal health and growth from middle-class backgrounds (Nelson and Nettleton, unpublished results), the average energy intakes of children up to 5 years fell at or above the RDI, but the average intakes of older children fell below the RDI, dropping to an average of $90 \%$ of the RDI by age 12 . This suggests that the RDI for the older children may be too high (also reported by Durnin et al. 1974) further compounding the problem with group (b).

A more promising explanation for the differences in growth on apparently similar diets lies in the variability of intake around the mean. By looking at the coefficient of variation (standard deviation/mean) in Table $\mathbf{~}$, we can see that the intakes of group (a) cluster much more closely about the mean than the intakes of group (b). This implies that there are many more children in group (b) than in group (a) with very low intakes, hence the greater number of children whose growth is likely to be restricted by inadequate diet. At the same time, however, 
there must be more children in group (b) than group (a) with very high intakes, so why are there not the commensurate number of tall children in group (b)? The variability of intakes solves only half the problem, perhaps because the distribution of intakes is not normal (see Fig. 2).

We must therefore consider other non-dietary factors which are correlated with growth. These include parental height, sibling number, household density (persons

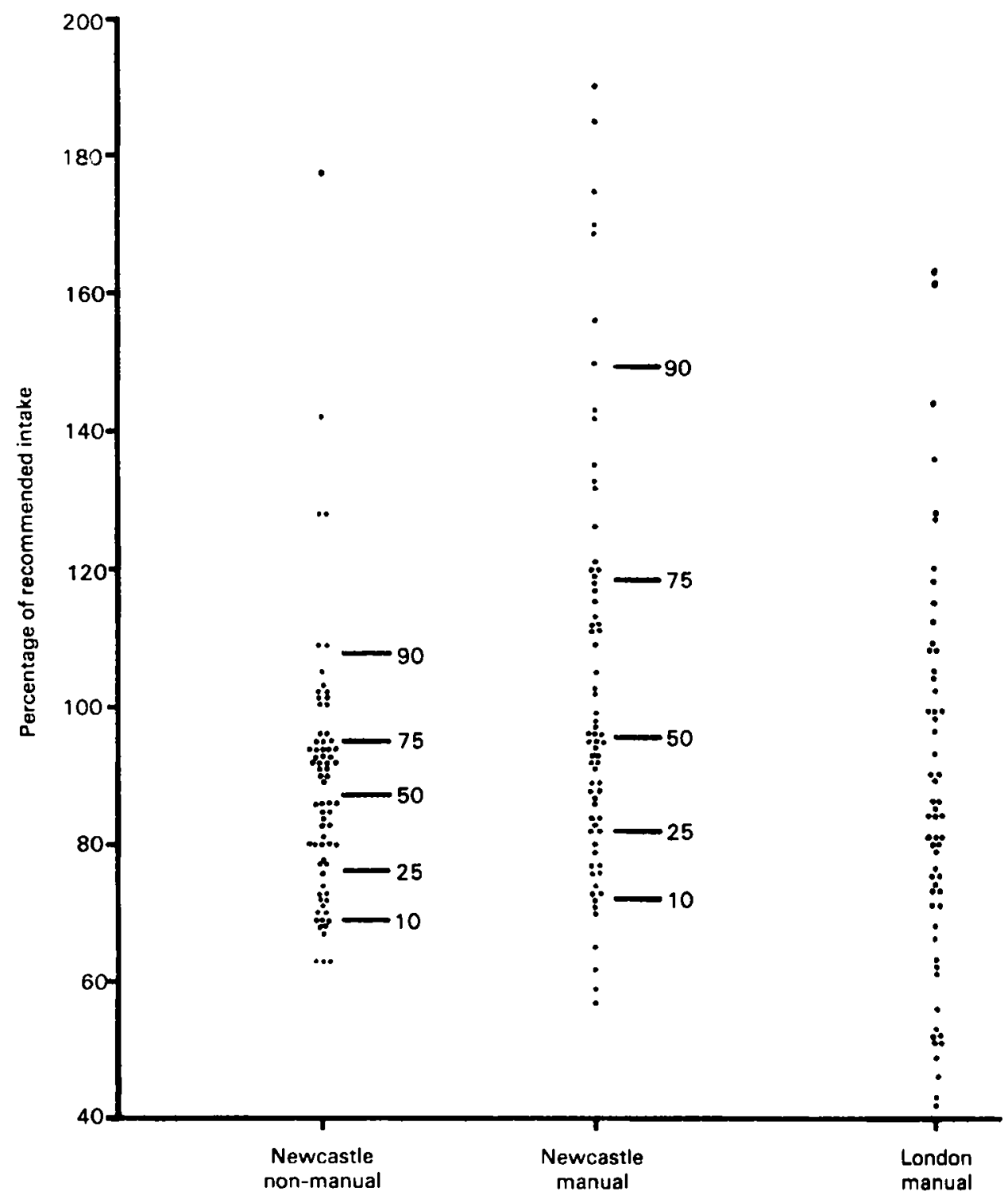

Fig. 2. Individual energy intakes of Newcastle non-manual and manual social class children and London manual social class children, expressed as a percentage of the Recommended Intake (DHSS, 1969) — designates the Ioth, $25^{\text {th }}, 5^{\text {oth }}, 5^{\text {th }}$ or 90 th percentile, as indicated. 
per room), health and sanitation, as well as social class. Given the backgrounds of the Newcastle non-manual and the London manual children, we can safely assume that all the factors negatively correlated with growth (large families, poor health, poor sanitation, overcrowding) were more prevalent amongst the London children. If that is the case, do these non-nutritional factors constitute an 'environmental handicap', implying that a diet adequate for the upper class children is not adequate for the lower class? I think that the answer to this question is 'yes', based on the fact that while intake goes up when moving down the social scale, mean height decreases.

\section{Dietary standards related to 'environmental handicap'}

Let us now consider ways in which an assessment of dietary adequacy can be made to relate to growth. As we have seen, an assessment based on mean values of the RDI fails to take into account three things: the variability of intake; the relationship of RDI to median intake at different ages; the effectiveness of diet in promoting growth and health in different environmental circumstances.

This occurs because the RDI is an external standard, applicable to groups, not individuals, and is applied uniformly across all social classes.

In essence, we require an internal standard, related to intake and growth by age, which is sensitive to 'environmental handicap'. A standard based on the distribution of absolute intakes at each year of age in each of two social classes ('upper' and 'lower') or other external parameter of growth and 'environmental handicap' would fulfil these requirements.

In the absence of this ideal standard, we can continue to use the RDI and the coefficient of variation to illustrate exactly why such internal standards are necessary. Let us return to the Newcastle and London results. If we consider the

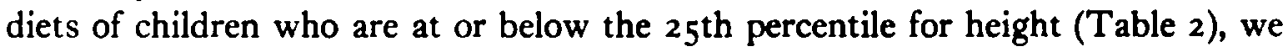
see that the mean energy intakes of the Newcastle non-manual and the London manual are identical when expressed as a percentage of the RDI. The variability, as expected, is much greater in the London group, and the relative risk of being below the $25^{\text {th }}$ percentile for height is twice as great in the London manual as the Newcastle non-manual group. (Bear in mind that for a normally distributed population the risk is exactly $25 \%$ ). The measures of intake and growth of the Newcastle manual children provide the links between the two extremes. While the

Table 2. Mean energy intakes of Newcastle and London children at or below the $25_{\text {th }}$ percentile for height, expressed as a percentage of the Recommended Intake

\begin{tabular}{|c|c|c|c|}
\hline & $\begin{array}{c}\text { Newcastle } \\
\text { non-manual }\end{array}$ & $\begin{array}{c}\text { Newcastle } \\
\text { manual }\end{array}$ & $\begin{array}{l}\text { London } \\
\text { manual }\end{array}$ \\
\hline Mean energy intake ( $\% \mathrm{RDI})$ & $7^{8}$ & 96 & $7^{8}$ \\
\hline Variability & O. I 7 & 0.29 & 0.35 \\
\hline $\begin{array}{l}\text { Percentage of children at or } \\
\text { below the } 25^{\text {th }} \text { percentile for } \\
\text { height }\end{array}$ & 15 & 21 & 32 \\
\hline
\end{tabular}


mean energy intake increases from Newcastle non-manual to manual, a higher proportion of the manual children falls below the $25^{\text {th }}$ percentile for height. The manual children would thus appear to bear a greater 'environmental handicap' than the non-manual children, being obliged to increase their energy intake in order to protect adequate growth. If this nutritional protection is not available, as in the case of the London children, the proportion of short children increases sharply. The non-manual and manual populations thus appear to be in two distinct populations with different nutritional requirements. This is further illustrated in Fig. 3, relating the absolute energy intake and growth of the Newcastle non-manual and manual 3 year olds. It can be seen that height is far less sensitive to change in intake in the manual than in the non-manual children. This implies that diet is less efficient in promoting growth amongst the manual children.

\section{Two new 'standards'}

If the London dietary survey results are to be assessed meaningfully, they must be compared with the correct standard. We can create two new 'standards' using

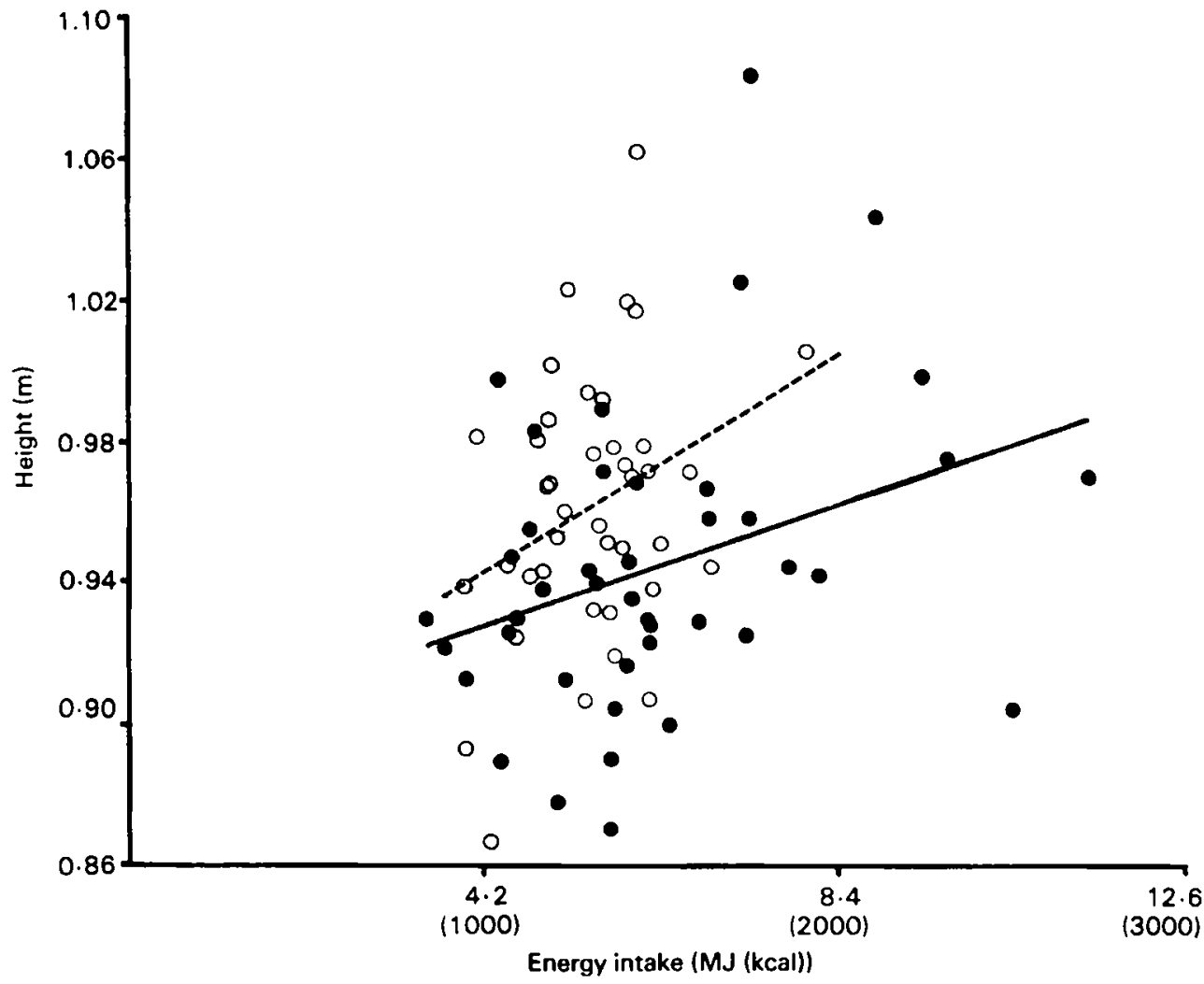

Fig. 3. Height $\tau$. cnergy intake by social class in Newcastle 3 year olds. (O-....) non-manual, (-) manual.

Regression line equations:

Non-manual $Y=0.0063 x+87 \cdot 9$.

Manual $Y=0.0034 x+89.5$. 
the Newcastle results, in order to find an expression of dietary adequacy which will match the distribution of height of the London children illustrated in Fig. I (b). In Fig. 2, the intakes of the Newcastle and London children are plotted by social class against \%RDI. The Newcastle scattergrams are divided into six percentile bands in order to create a non-manual and a manual standard. The London results can now be mapped onto each of these 'standards' in order to plot two sets of percentile distributions. For example, the intake of a London child which is $95 \%$ of the RDI will fall on the $75^{\text {th }}$ percentile of the non-manual standard, but just below the 5oth percentile on the manual standard. By using this same mapping technique for the intakes of each of the London children, two sets of percentile distributions can be created, representing two assessments of dietary adequacy. These are illustrated in Fig. 4.

How are these assessments to be interpreted? Basically, we are looking for goodness of fit between our dietary distribution and our height distribution. It is easy to see that the manual standard produces a distribution of intakes not unlike that for height, while the non-manual standard produces a distribution which bears little resemblance to that for height. Statistically, comparisons between diet and height distributions based on $X^{2}$ give values of 79.2 and 4.0 for the non-manual and manual, with associated probabilities of $P<0.001$ and $P=0.55$, respectively. The latter value represents a statistically 'good' fit for two separate sets of information.

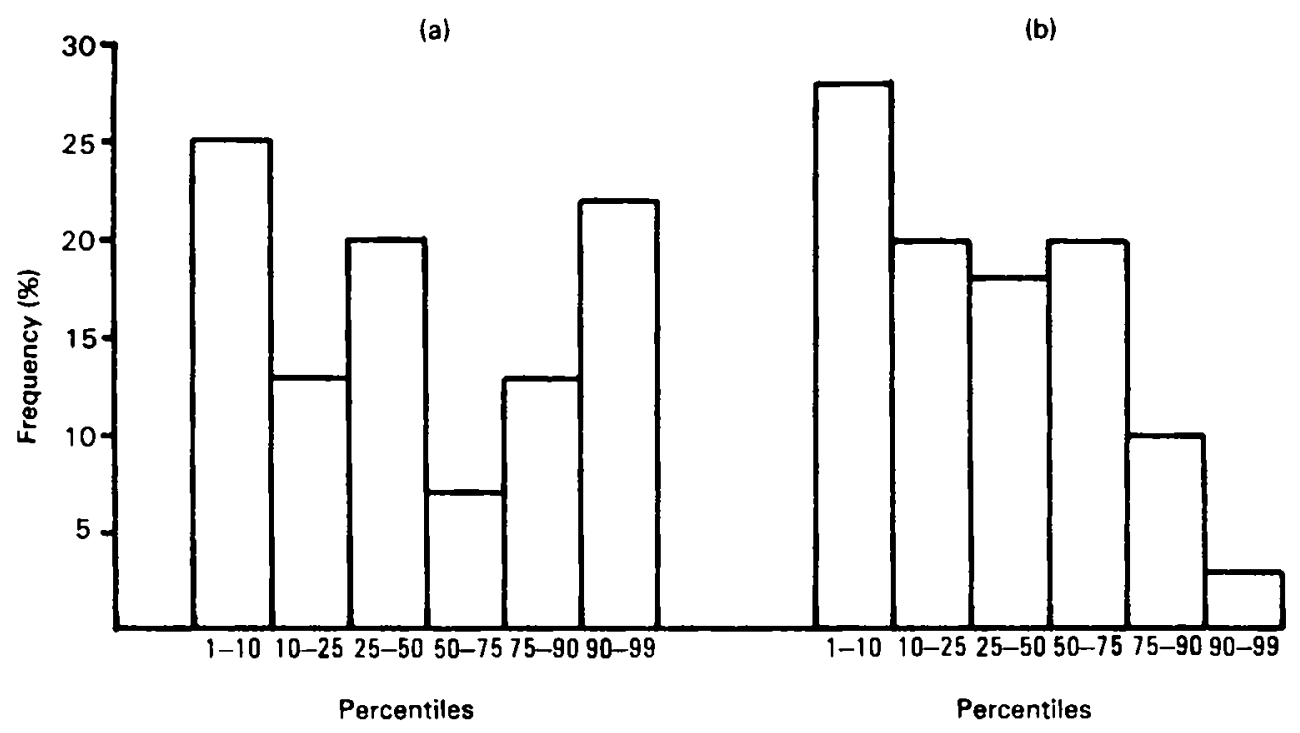

Fig. 4. Distribution of individual London children's energy intakes (expressed as a percentage of the Recommended Intake) when plotted against the (a) Newcastle non-manual or (b) manual 'standards'. 


\section{Conclusion}

Using information from two surveys, it has been possible to demonstrate the need for two standards of dietary adequacy. While the examples illustrated have been based on estimates of individual energy and nutrient intake expressed as a percentage of the RDI, ideal standards would be based on the percentile distributions of absolute intakes at each year of age. By grouping information from children of similar social or environmental backgrounds, an element of 'environmental handicap' can be incorporated into the standard which will then better express the relationship between diet and growth. A more meaningful picture of dietary adequacy can then be derived from surveys based on the measurement of diet alone.

I would like to thank Professor A. M. Thomson and Miss A. E. Black for allowing access to unpublished results from their Newcastle study.

\section{REFERENCES}

Black, A. E., Billewicz, W. Z. \& Thomson, A. M. (1976). Br. f. Nutr. 35, 105.

Bransby, E. R. \& Fothergill, J. E. (1954). Br. F. Nutr. 8, 195.

Department of Health and Social Security (1969). Rep. publ. Hlth med. Subj., Lond. No. 120. London: H.M. Stationery Office.

Department of Health and Social Security (1975). Rep. Hlth Soc. Subj. No. Io. London: H.M. Stationery Office.

Durnin, J. V. G. A., Lonergan, M. E., Good, J. \& Ewan, A. (1974). Br. f. Nutr. 32, 169. Marr, J. W. (1965). Nutrition 19, 18.

Nelson, M. \& Naismith, D. J. (1979). J. Hum. Nutr. 33, 33.

Tanner, J. M., Whitehouse, R. H. \& Takaishi, M. (1966). Archs Dis. Childh. 4I, 454.

Widdowson, E. M. (1947). Spec. Rep. Ser. med. Res. Coun. No. 257. London: H.M. Stationery Office. 